\begin{tabular}{ccc}
\hline International Journal of Engineering \& Technology, $7(4.3)(2018) 222-227$ \\
SPC & Website: www.sciencepubco.com/index.php/IJET \\
Research paper & Technology \\
\hline
\end{tabular}

\title{
Managing Dynamically Changing Traffic Flows
}

\author{
M. Karaeva ${ }^{1}$, N. Napkhonenko ${ }^{1}$, V. Perevozniuk ${ }^{2}$ \\ ${ }^{1}$ Federal state budget educational institution of higher professional education "Platov South-Russian State Polytechnic University \\ $(N P I)^{\prime \prime}$, \\ ${ }^{2}$ Kremenchuk Mykhailo Ostrohradskyi National University, \\ *Corresponding author E-mail: mari.karaeva@gmail.com
}

\begin{abstract}
The brief analysis of publications in the field of transport development, the organization and management of urban passenger traffic in the conditions of constantly changing passenger traffics is carried out. The efficiency of using logistic methods is proved by optimization of public passenger transport of the megalopolis. The factors influencing regularity of passenger traffics formation and their dynamic spatial distribution taking into account the main communications between passenger formed points and service providers are revealed. For improvement of traffic flows management the relevance of development of new mathematical models and methods considering relationship of cause and effect between the input and output parameters is established. Methods of solving large-size problems in the conditions of difficult criterion function are considered. Advantages and the prospects of meta-heuristic methods application - genetic algorithms - are shown at the solution of the transport tasks characteristic of unstable streams.

For solving the objective using a set of genes is proposed which elements represent a chromosome with a certain set of decisions. Restrictions are formulated and operators of casual changes for a work of genetic algorithm are defined. The algorithm allowing to define and range the key input parameters influencing process of providing transport services and to receive parameters for the output correlation analysis is obtained.
\end{abstract}

Keywords: differential equations, development of logistic models, chromosome, gene, genetic algorithm, linear and nonlinear architectures, logistics meta-heuristic methods, organization of transport, optimization methods, passenger traffic, population, system of urban passenger transportation.

\section{Introduction}

The efficiency of economic relations and mobility of the population directly depend on transport connection speed. The optimum economic and social effect can be reached only at a certain speed of delivery. In transit freights the effect is expressed in release of current assets of the enterprise while in transit passengers release of people time which can be used in other purposes is defining. Improvement of life quality of the population, strengthening of the country territorial unity, improvement of business level, creation of more favorable conditions for realization of each Russian region potential economic and social opportunities is possible only at reduction in cost and acceleration of transportations on all kinds of transport.

Models should be developed which not only describe process of transportation and separate stages of his organization, but also allow to operate this process, for the purpose of increase in quality of transportation and reduction of waiting time by the passenger of service on the place of landing. All this causes need of qualitatively creation new control systems capable to react flexibly to constantly changing system operating conditions [3].

The purpose of the work is optimization of city passenger traffic management process in the conditions of dynamically changing streams, with a possibility of accounting of necessary parameters number for adoption of the adequate solution of time at present. Basis for optimization of the organization and management is the formulation of criterion that means the formalized problem definition. The task of transportations management can be considered as optimum distribution of resources. For this purpose criterion function should be defined and its optimum value should be calculated in the conditions of the objective [4].

Formally, the problem of optimum control is put for definition of a state (trajectory) vector $x(t) \dot{\tau} \mathbf{R}^{n}$, a vector of management $u(t) \dot{\boldsymbol{\chi}} \mathbf{R}^{m}$, a vector of static parameters $\rho \dot{\boldsymbol{\chi}} \mathbf{R}^{q}$, initial time $t_{0} \dot{\chi} \mathbf{R}$ and final time $t_{f} \dot{\chi} \mathbf{R}$, where time $t \dot{\mathcal{\zeta}} \hat{g}_{0}, t_{f} \grave{\mathrm{u}}$ is independent size and serves for optimization of criterion function of $J$ :

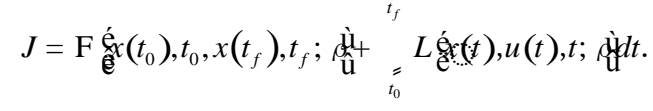

Optimization of function $J$ is carried out taking into account differential (dynamic), $\not(t)$, trajectory $\left(C_{\min }\right.$ and $\left.C_{\max }\right)$ restrictions and limits of optimality and $\mathrm{F}_{\text {min }}$ and $\mathrm{F}_{\text {max }}$ :

$$
\begin{aligned}
& x(t)=f \text { éd }(t), u(t), t ; \text { d्̀ } \\
& C_{\min } £ C \text { édx }(t), u(t), t \text {; 哭 } C_{\text {max }} \text {; }
\end{aligned}
$$

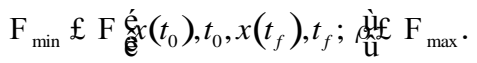


Vectors of a state, management and parameters can be presented as follows:

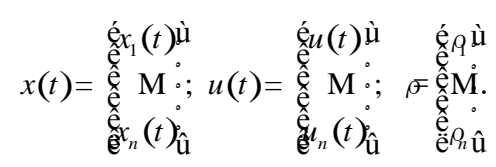

The differential equation (2) represents dynamics of system, at that time when the index of productivity of $J$ is a measure of quality of a trajectory. When it is desirable to minimize the index of productivity, it is necessary to receive low value $J$. On the other hand, when it is necessary to maximize the index of productivity, it is necessary to provide higher value $J$ [8].

As a rule, the problem of optimum control is divided into the stages or phases connected $\rho \dot{\chi}[1, \mathrm{~K}, P]$, with each other significantly. The multiphase problem of optimum control is put as follows:

$$
J=\bigotimes_{k=1}^{P} J^{(k)},
$$

where $J^{(k)}$ - value of optimality criterion on each phase $k$. Phase values are also defined taking into account differential $\&(t)$, trajectory ( $C_{\min }$ and $C_{\max }$ ) restrictions and limits of optimality $\mathrm{F}_{\text {min }}$ and $\mathrm{F}_{\text {max }}$, also communication conditions between phases ( $L_{\min }$ and $L_{\max }$ ):

$$
\begin{aligned}
& x^{(k)}(t)=f \underset{\mathrm{e}^{\prime}}{\dot{e}^{(k)}}(t), u^{(k)}(t), t ; \rho^{(k)} \stackrel{\mathrm{u}}{\mathrm{u}}
\end{aligned}
$$

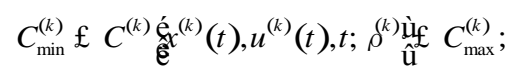

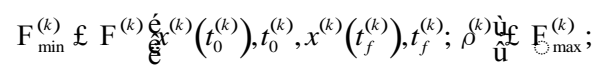

$$
\begin{aligned}
& L_{\min }^{(s)} £ L\left(x^{\left(l_{s}\right)}\left(t_{f}^{\left(l_{s}\right)}\right), u^{\left(l_{s}\right)}\left(t_{f}^{\left(l_{s}\right)}\right), \rho^{\left.l_{s}\right)}, t_{f}^{\left(l_{s}\right)},\right. \\
& \left.x^{\left(r_{s}\right)}\left(t_{f}^{\left(r_{s}\right)}\right), u^{\left(r_{s}\right)}\left(t_{f}^{\left(r_{s}\right)}\right), \rho^{\left(r_{s}\right)}, t_{f}^{(r)}\right) £ L_{\max }^{(s)},
\end{aligned}
$$

where $\mathrm{s}-$ number of communication between couple of a phase, $\mathrm{r}_{\mathrm{s}}$ and $l_{s} \dot{\tau}[1, \mathrm{~K}, s]$ - the right and left phases respectively.

Applications of numerical methods for the solution of transportation process management optimization problems are the cornerstone three main components, namely: methods of the solution of the differential equations and integration of functions; methods of the nonlinear algebraic equations systems solution; methods of the optimization nonlinear problems [5].

Methods of the solution of the differential equations are required for all numerical methods of optimum control. In indirect approach numerical solutions of the differential equations are combined with methods of the nonlinear equations, and in direct approach - with methods of the optimization nonlinear problems solution.

For the purpose of achievement of the similar tasks solution maximum efficiency especially relevant there is a problem of the quantity choice considered during the modeling and optimization of parameters and numbers of possible conditions of system. It is connected with the fact that such difficult system as passenger traffic in the large city, can be described taking into account hundreds of significant parameters and states that dictates need of simplification of a task, her decomposition and reduction of the considered parameters number.

For the solution of an objective of passenger traffic management process optimization it is offered to use the genetic algorithm adapted to objective conditions. At the same time it is necessary to consider concepts of a chromosome, a gene, population and also operators of casual changes [11].

On the basis of calculation of criterion function and the analysis of verbal indicators the following restrictions have been formulated $[1,2]$ :

1. Number of places $N^{m}$ :

$$
N_{z}^{m} \leq N_{z}^{v m},
$$

where $N_{z}^{v m}$ - the nominal capacity of the bus $z$.

2. Period of a route operation $M^{r}(\mathrm{~h})$ :

$$
\begin{gathered}
T_{\min }^{r} \leq M^{r} \leq T_{\max }^{r} ; \\
T_{\min }^{r} \leq 6 h ., T_{\max }^{r} \leq 16 h .
\end{gathered}
$$

3. Time in a dress $T^{n}(\mathrm{~h})$ :

$$
\begin{gathered}
T_{\min }^{n} \leq T^{n} \leq T_{\max }^{n} ; \\
T_{\min }^{n} \geq 8 h, T_{\max }^{n} \leq 12 h .
\end{gathered}
$$

4. Passing of the $a_{i}$ bus through all subsequent stops of a route, since an initial stop $x_{i}, i=\overline{j, k}$, where $j$-number of a stop of the movement beginning.

5. The minimum time of a passenger change on stopping points $t_{k}^{\alpha}(\mathrm{min})$ :

$$
t_{k}^{\alpha} \leq t_{k}^{o s}
$$

where $t_{k}^{o s}$ - time allowed for a stop according to the schedule at $\mathrm{k}$ stop.

6. Time of the bus movement

$$
t_{i, j}^{m}>t_{i, j}>t_{i, j}^{a}, \quad i=\overline{1, k-1}, \quad j=\overline{2, k}
$$

Time between stops has to be more than minimum allowed traffic regulations and safe movement less the most admissible time providing quality of service.

7. The number of the rolling stock on the line $A^{m}$ shouldn't exceed total of buses in the park:

$$
A^{m} \leq A .
$$

8. The maximum waiting time at a stop $t_{\max }^{\hat{1}}$.

As a chromosome the option of decision elements task consisting solution - genes is considered. A set of the decision make population versions [7].

For the solution of an objective and creation of a chromosome as input parameters have been used:

For the solution of an objective and creation of a chromosome as input parameters have been used:

- time of a motion start of each bus for lines;

- conditional number of a stop of a motion start;

- the number of the made flights in time in a dress;

- the number of the rolling stock on the line.

Taking into account these parameters the offered chromosome A will have an appearance:

$$
\begin{aligned}
& A=\left(a^{1}, b^{1}, d^{1}, g_{1,2}^{1}, g_{2,3}^{1}{ }^{1 / 4}, g_{i, j}^{1},{ }^{1 / 4}, g_{i-l, k}^{l}, m_{l}^{1} ;\right. \\
& a^{v}, b^{v}, d^{v}, g_{1,2}^{v}, g_{2,3}^{v}, 1 / 4, g_{i, j}^{v}, 1 / 4, g_{i-l, k}^{v}, m_{j}^{\gamma} \text {; } \\
& a^{z}, b^{z}, d^{z}, g_{1,2}^{z}, g_{2,3}^{z}, 1 / 4, g_{i, j}^{z}, 1 / 4, g_{i-l, k}^{z}, m_{k}^{z} 1^{\frac{\dot{\dagger}}{\dot{s}}}
\end{aligned}
$$

So, the gene $a=\left(a^{1}, a^{2}\right)$ bears information on the number of flights; the gene $b^{v}=\left(b_{1}^{v, N}, b_{2}^{v, N}, 1 / 4, b_{14}^{v, N}\right)$ the gene defines a start of motion of $v$ in minutes for $N$ flight $v=\overline{1, z}$, where $z$ - the number of buses on a route in work; the gene $d^{\prime}=\left(d_{1}^{p, N}, 1 / 4, d_{u}^{, N}, 1 / 4, d_{h}^{p^{N}}\right)$ the gene defines the beginning of the of $\mathrm{v}$ bus in minutes for $N$ flight where the z-number of buses on a route in work time

Gene 


$$
\begin{gathered}
g_{1,2}^{v, N}=\left({ }^{l} g_{1,2,1}^{v, N},{ }^{l} g_{1,2,2}^{v, N},{ }^{l} g_{1,2,3}^{v, N}\right), 1 / 4, \\
g_{j, i+1}^{v, N}=\left({ }^{l} g_{j, i+1,1}^{v, N},{ }^{l} g_{j, i+1,2}^{v, N},{ }^{l} g_{j, i+1,3}^{v, N}\right), 1 / 4, \\
g_{k-1, k}^{v, N}=\left({ }^{l} g_{k-1, k, 1}^{v, N},{ }^{l} g_{k-1, k, 2}^{v, N},{ }^{l} g_{k-1, k, 3}^{v, N}\right)
\end{gathered}
$$

represent vectors of $\mathrm{v}$ route sites passing temporary intervals by the flight $\mathrm{N}$ bus where $i=\overline{1, k}$.

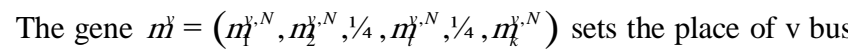
motion $v=\overline{1, z}$, where $\mathrm{z}$ - the number of buses on a route in work time.

Operators of casual changes which will transform chromosomes are developed for designing of HECTARE [****], make the analysis of new chromosomes and make selection of chromosomes, perspective for development. At realization of HECTARE in relation to an objective it is necessary to specify and concretize the used operators. As the operators of a reproduction (OR) are used a two-parental, multiparental crossing over, and as operators of a mutation (OHM) the multipoint mutation is applied.

As an example the two-parental crossing over the Cross-country is considered Kross $2\left({ }^{l} P,{ }^{d} P\right)$. Two chromosomes parents ${ }^{l} P,{ }^{d} P$

(Fig.1) participate in operation. As a result of the operation Crosscountry performance $\operatorname{Kross} 2\left({ }^{l} P,{ }^{d} P\right)$ two new chromosomes ${ }^{1} C$

and ${ }^{2} C$ descendants and by exchange of genes symbols are designed. To the first descendant pass symbols of the first parent genes to a gap point inclusive and symbols of genes of the second parent after a gap point. The second descendant is designed by inheritance of genes symbols of the first parent after a point of a gap and the second parent to a gap point [***]. Symbols of genes act as a point of a gap $a^{z}, b^{z}, d^{z}, g_{1,2}^{z, N}, g_{j, i+1}^{z, N}, g_{k-1, k}^{z, N}, m$. Symbols in genes of descendants are located on the places corresponding to their arrangement in chromosomes parents. Indexes of these symbols are also generated in a random way. The «Crossing over» operator serves in an objective for receiving the chromosomes descendants, repeatedly meeting parents and who are candidates for entry into the current population.

At realization multiparental Cross-belief $\operatorname{Kross} M\left({ }^{l} P, \mathrm{~K},{ }^{d} P\right)$ the Cross-country $k$ of parents take part in operation and to similarly two-parental crossing over exchange of genes symbols where is made.

$a^{z}, b^{z}, d^{z}, g_{1,2}^{z, N}, g_{j, i+1}^{z, N}, g_{k-1, k}^{z, N}, m^{\tilde{z}}$, where $k=\operatorname{Rnd}(1, g)$.

At realization of a gene crossing over $\operatorname{GKross}\left({ }^{l} P,{ }^{d} P\right)$ two parents participate in operation ${ }^{l} P,{ }^{d} P$. Unlike the operation Kross 2 exchange of symbols is made only within the $I$ gene At multipoint "Mutation" (Fig. 2) the chromosome ${ }^{l} P$ chosen in a random way from population is exposed to casual changes. For this purpose the number of the made changes is defined:

$k^{m u t}=\operatorname{Rnd}(1, w)$,

where $w=(((k-1)+14+k) \times \alpha) \times z-$ the chromosome size in symbols. The chromosome is considered as a vector ${ }^{l} P=\left({ }^{l} c_{1},{ }^{l} c_{2}, 1 / 4,{ }^{l} c_{r}, 1 / 4,{ }^{l} c_{w}\right)$, elements of which are symbols of genes. Then inverting is carried out: $c_{T_{b}}=\left|c_{T_{b}}-1\right|$,

where $T_{b}=\operatorname{Rnd}(1, w), b=\overline{1, k^{m u t}}$.

In this case the descendant of $\mathrm{C} 1$ has an appearance:

$$
\begin{aligned}
& C 1={ }^{l} c_{1}, 1 / 4,{ }^{l} c_{T_{1}-1},\left|{ }^{l} c_{T_{1}-1}-1\right|,{ }^{l} c_{T_{1}+1}, 1 / 4,{ }^{l} c_{T_{b}-1}, \\
& \left|{ }^{l} c_{T_{b}-1}-1\right|,{ }^{l} c_{T_{b}+1}, 1 / 4,{ }^{l} c_{T_{k}-1},{ }^{l} c_{T_{k}-1} \mid,{ }^{l} c_{T_{k}+1}, 1 / 4,{ }^{l} c_{w} .
\end{aligned}
$$

At a gene mutation of «Gmutation» $\left({ }^{l} P, I\right)$ the chromosome $\left({ }^{l} P\right)$ chosen randomly from population is exposed to casual changes which are made in the 1st gene. Numbers of genes correspond to their arrangement in a chromosome; the number of the made changes is defined as $T^{m u t}=\operatorname{Rnd}(1, w)$ where $\mathrm{w}-$ the size of the 1st gene in symbols:

$$
{ }^{l} P={ }^{l} c_{1},{ }^{l} c_{2}, 1 / 4,{ }^{l} c_{r}, 1 / 4,{ }^{l} c_{w} .
$$

As a result of this operator application we receive the descendant

$$
C 1={ }^{l} c_{1},{ }^{l} c_{2}, 1 / 4,{ }^{l} c_{T}, 1 / 4,{ }^{l} c_{w} .
$$

Operation selection of «Select» ${ }^{l} P, \mathrm{~K},{ }^{k} P, I,{ }^{1} C, \mathrm{~K},{ }^{2} C, \mathrm{~K},{ }^{k} C$ represents modification of an elite recombination with a local competition between the descendant and the parent, closest to the descendant. For performance of operation the concept of two chromosomes proximity measure is entered ${ }^{l} P$ and ${ }^{d} P$ :

$$
\begin{gathered}
D\left({ }^{l} P,{ }^{d} P\right)=\left(K^{a} D^{a}+K^{b} D^{b}+\right. \\
\left.+K^{d} D^{d}+K^{g} D^{g}+K^{m} D^{m}\right)
\end{gathered}
$$

where $K^{\alpha}, K^{\beta}, K^{\delta}, K^{\gamma}, K^{\mu}$ - weight coefficients for genes $a^{z}, b^{z}, d^{d}, g_{1,2}^{z, N}, g_{j, i+1}^{z, N}, g_{k-1, k}^{z, N}, m^{z}$;

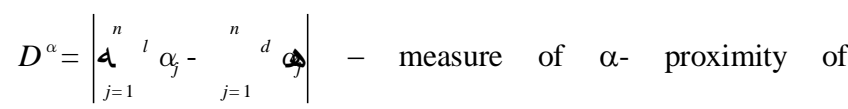
chromosomes ${ }^{l} P$ and ${ }^{d} P$;

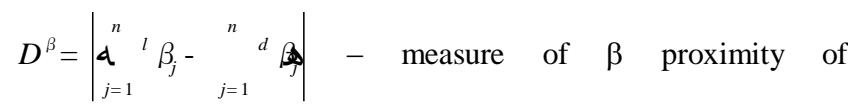
chromosomes ${ }^{l} P$ and ${ }^{d} P$; $D^{d}=\left|d_{j=1}^{n}{ }^{l} d_{j}-{ }_{j=1}^{n}{ }^{d} d s\right|-$ measure of $\delta$ proximity of chromosomes ${ }^{l} P$ and ${ }^{d} P$;

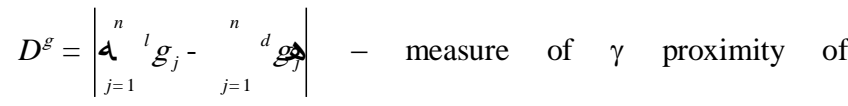
chromosomes ${ }^{l} P$ and ${ }^{d} P$; 

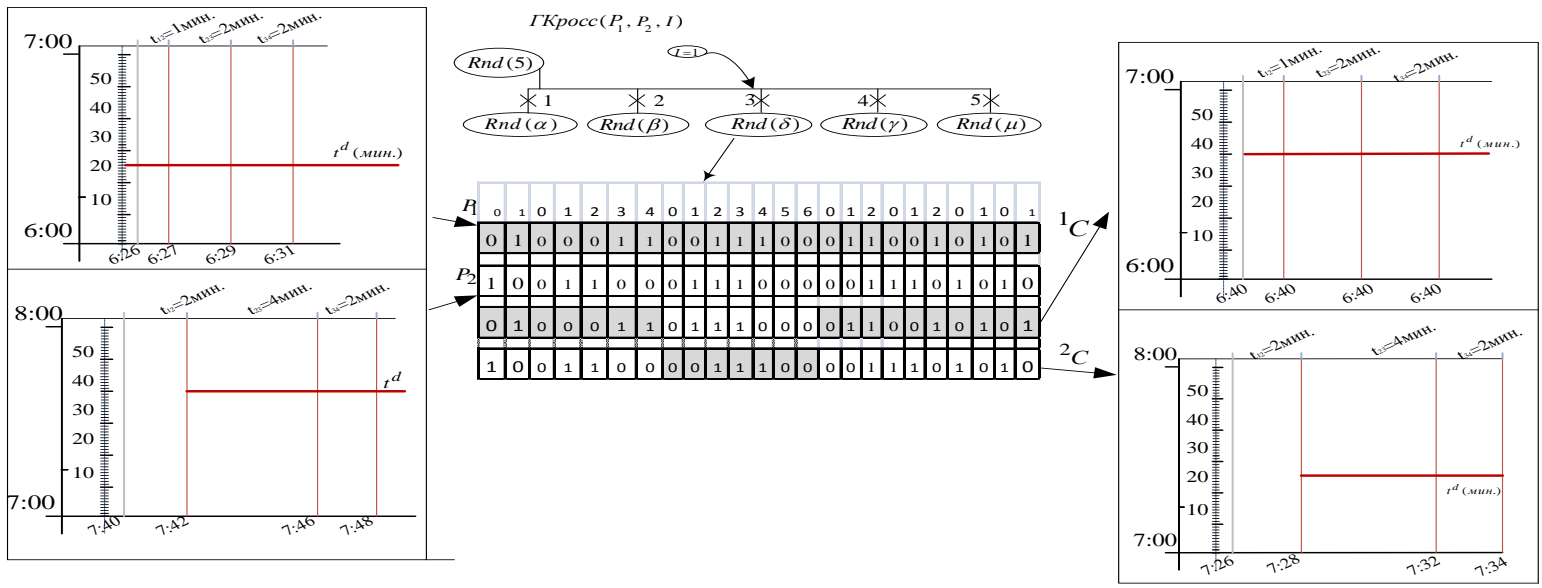

Fig. 1: Realization of Gene Crossing over operator for HECTARE of passengers transportation process optimization

$\left(P_{1}\right)$

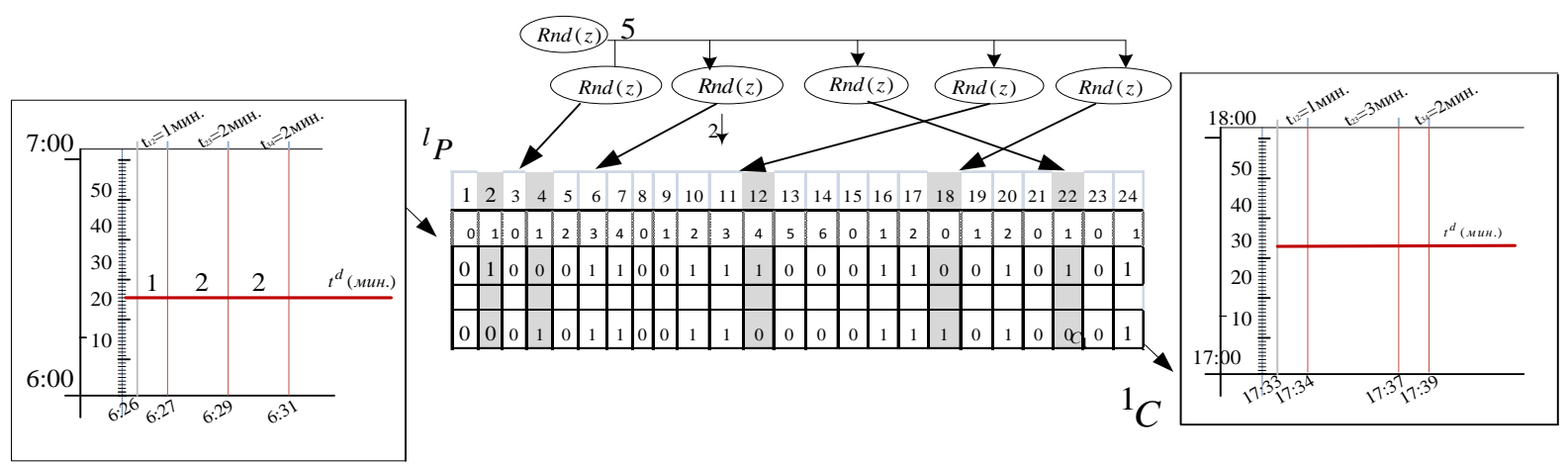

Fig. 2: Realization of the operator multipoint "Mutation" for HECTARE of passengers transportation process optimization.

$D^{m}=\left|\begin{array}{lll}d_{j=1}^{n} & { }^{l} m_{j}-{ }_{j=1}^{n} & { }^{d} n\end{array}\right|-$ measure of $\mu$ proximity of

chromosomes ${ }^{l} P$ and ${ }^{d} P$.

After performance of OHMS and the SHOUTING for all chromosomes parents and descendants is calculated proximity degree. If the descendant surpasses the closest parent, then he takes the place of the parent in population.

The main idea of genetic algorithms is the organization of "fight for existence" and "natural selection" among these decisions $[7,8]$. Designing of the modified genetic algorithm within an objective (MGA) includes two stages. In a generalized view the block diagram of HECTARE of city passenger traffic process management optimization is provided on Figure 3.

One of features of inherent HECTARES, the fact that the search result doesn't depend on initial values of initial parameters is, however in case search begins with population at which there are perspective chromosomes corresponding to local minima or close to them, then time of search can be reduced.

Stage 1. At the first stage of an algorithm there is a preparation of initial population ${ }^{Q} P$. As initial population five groups of chromosomes with a certain set of genes have been chosen:

$$
{ }^{Q} P=\left({ }^{q 1} P,{ }^{q 2} P,{ }^{q 3} P,{ }^{q 4} P,{ }^{q 5} P\right),
$$

where ${ }^{q 1} P$ - group of chromosomes in which the interval of the movement $t^{d}$ between stopping points shouldn't be less

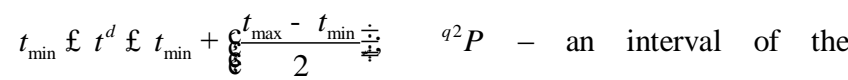
movement $t^{d}$ between stopping points which shouldn't exceed

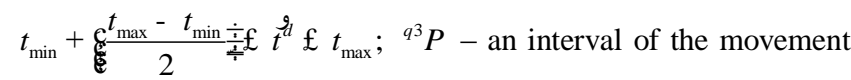
- an interval of the movement between stopping points which shouldn't exceed $t^{d} t_{\text {min }} £ t^{d} £ t_{\text {max }} ;{ }^{44} P$ - the number of the rolling stock it has to be equal $A_{\max } ;{ }^{q 5} P$ - group of chromosomes in which the start of the bus motion is carried out from various stops, starting with the first and finishing $k-k^{*}$, where $k^{*}$ is quantity of the last stops from where the start is forbidden.

Stage 2. At the second stage iterative change of population is made. For this purpose chromosomes parents are chosen, then operation of casual changes is carried out and the structure of population joins perspective descendants on the basis of criterion function calculation.

Condition of criterion function stop calculation is achievement of the maximum number of iterations of $\mathrm{N}^{\text {iter }}$. At the same time the choice from population of the best decision is made. This decision is presented in $\mathrm{P}$ chromosome form $\mathrm{P}^{*}$ at which the value of criterion function is the best among all chromosomes of the current population. Thus, we have received the rational decision containing it the schedule of the movement of buses which leads to a maximum of criterion function.

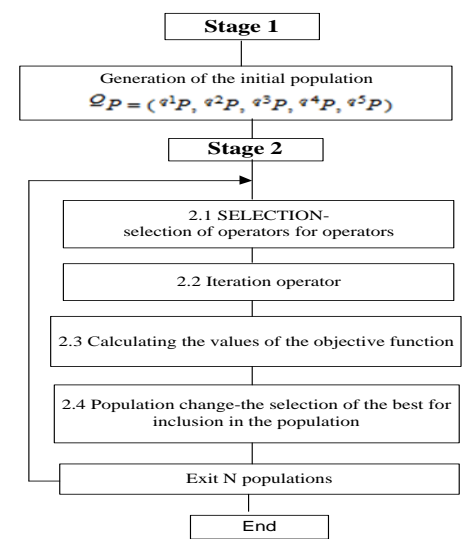

Fig. 3: Hectare Of Management Process Passenger Traffic Optimization. 
The sequence of the considered stages of an algorithm work repeats the set number of times.

For determination of efficiency of the offered methods and approaches on the basis of a genetic algorithm of transportations management optimization process on Transservice ATP-3 base the control system behind the movement of buses on a city route (Fig. 4) has been introduced and tested.

These links connect flows of information on the movement of the bus which remains and output to the monitor of the dispatcher computer in the form of the bus location coordinates on a route and a number of various schedules.

On the graphic linear scheme (Fig. 5) on ordinate axis astronomical time in a certain scale is postponed. Parallel to this straight line pass stopping points which conditional numbers are located at the beginning of straight lines in a view of thin gray lines. Besides, on an axis of an abscissa the schedule of each bus is shown the thin line, garage number of which settles down in a point of a start of motion and at the end of a straight line. At the moment when the thin line changes thickness, opposite to garage number of the bus the value of a deviation time from the schedule appears. This type of the schedule allows determining the minimum time the size of any bus deviation on the line from the schedule without analysis of the movement separate stages.

The last schedule of the executed movement (Fig. 6) also, as well as previous, shows astronomical time, conditional numbers of stopping points, garage numbers of buses, and in the form of the thin line the movement of the bus on the schedule. The curve of the executed movement is displayed by the thick line of the same color. If the curve of the movement is above a thin straight line, then the bus moves ahead of schedule the movements in case below a straight line, - with lag. At the end of a curve of the executed movement, deviation time from the schedule about one second is displayed near garage number of the bus. This schedule allows to define the most overloaded sites of a route for all day and intense sites of a route a "rush hours".

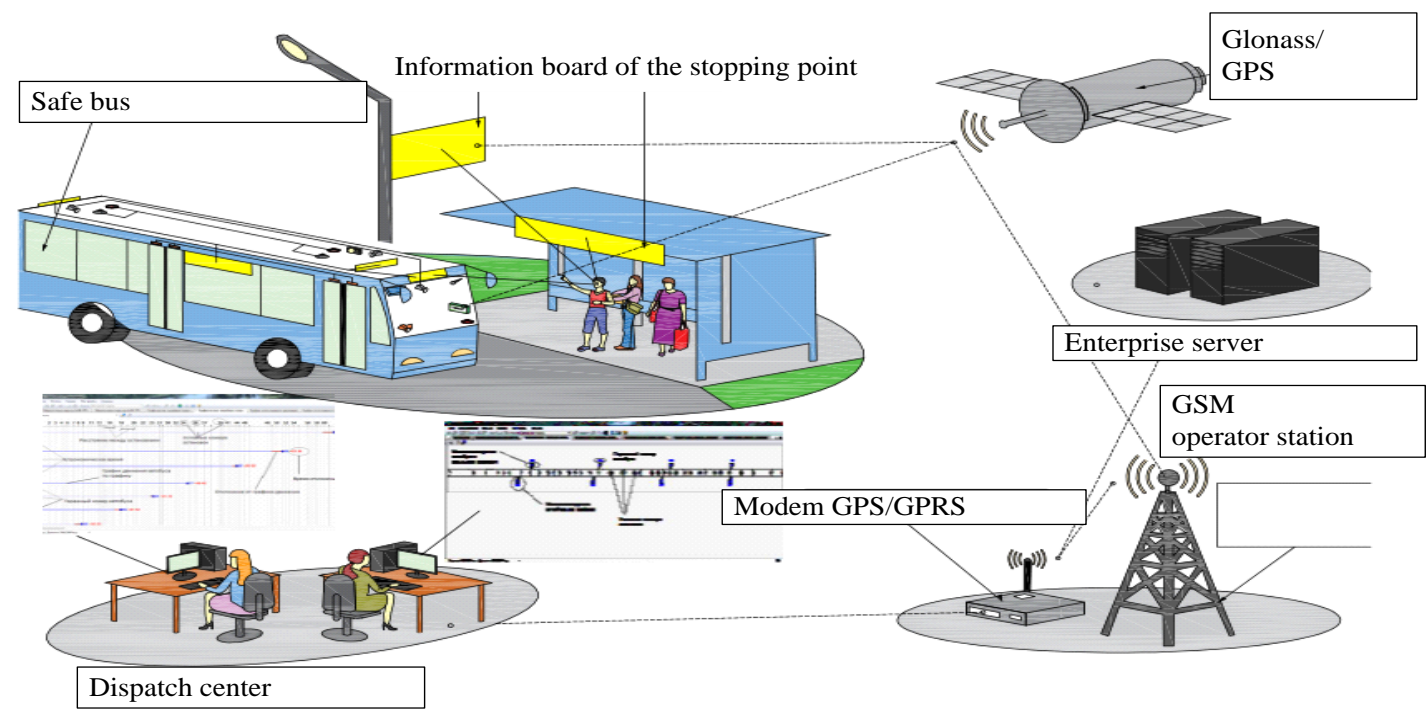

Fig. 4: The scheme of information streams course process between participants of process of transportation

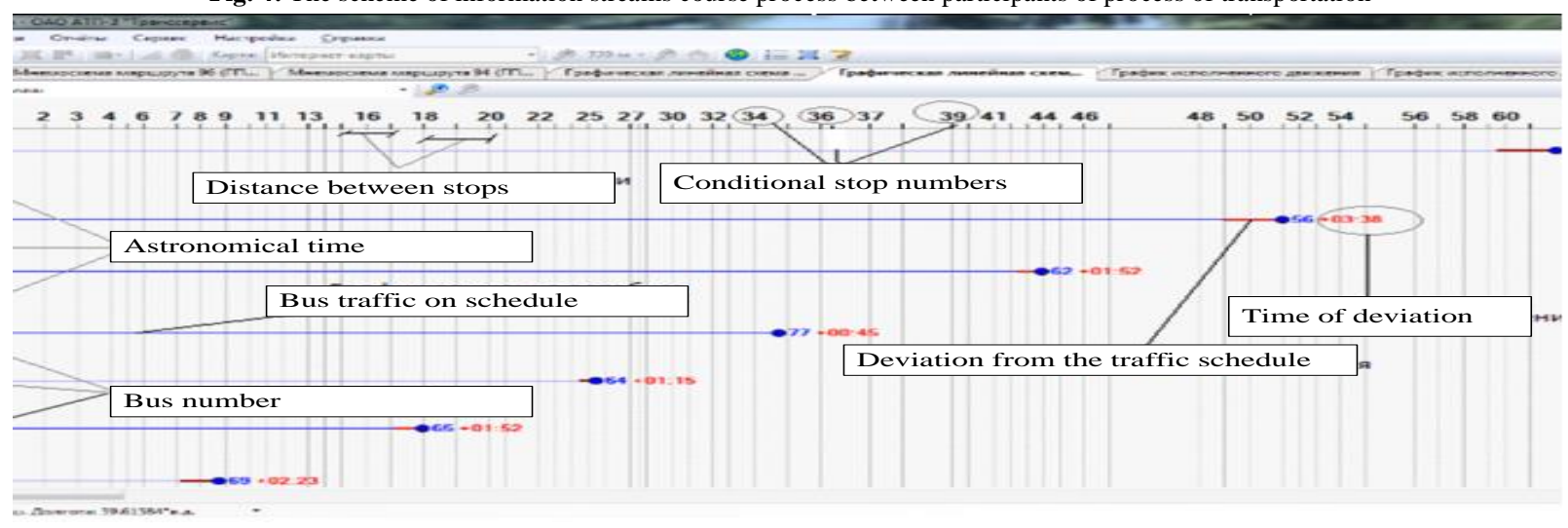

Fig. 5: The graphic linear scheme of the movement of buses along a route 


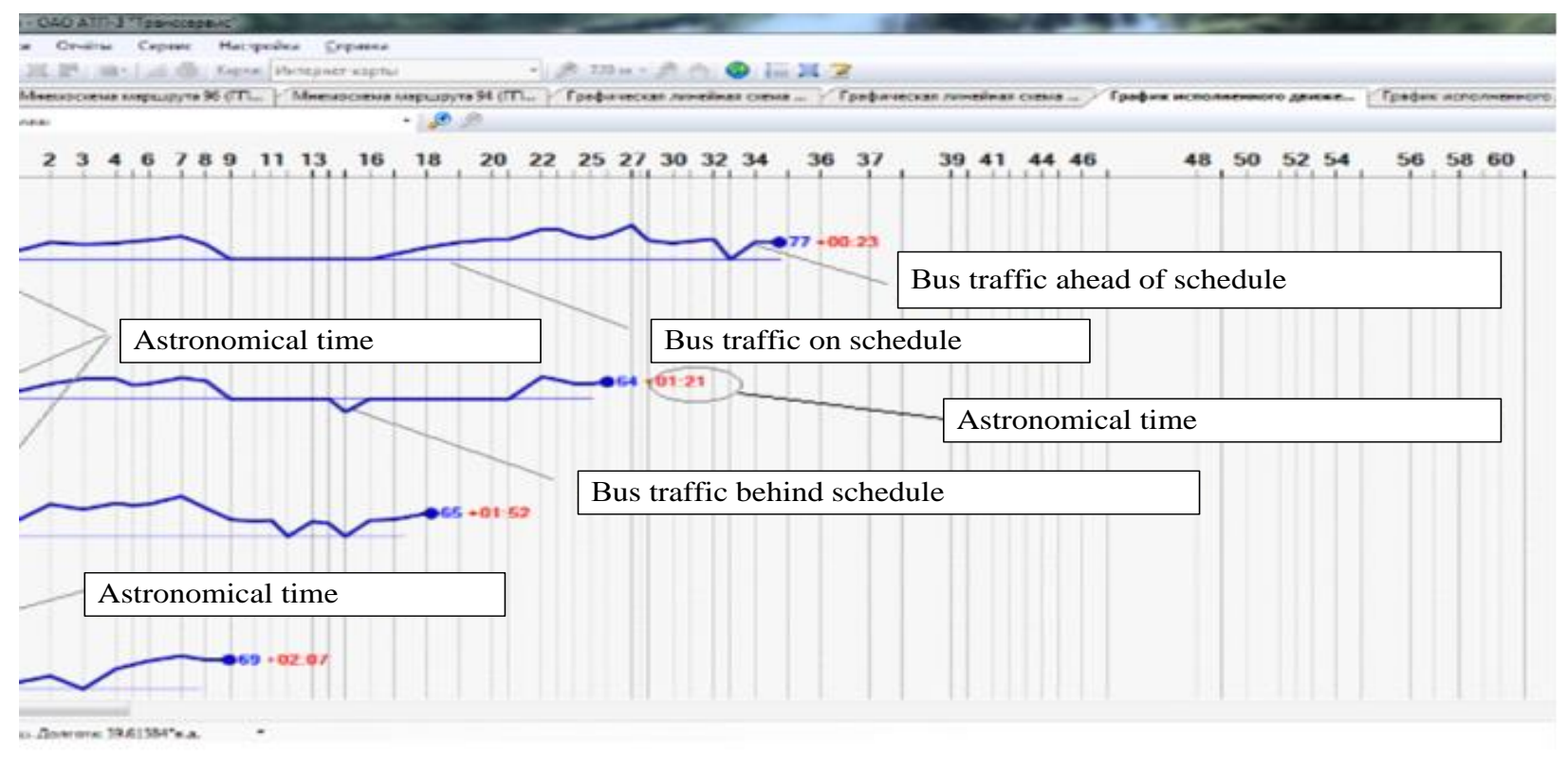

Fig. 6: The schedule of the executed movement of the bus on a route

In case the deviation from the schedule goes to the party of lag, more than for 7 minutes, the dispatcher analyzes a road situation according to information from the sensors installed by buses by which it is easy to determine whether the bus has got to a road jam or has descended from a route for technical reasons.

\section{Conclusions}

Thus, it is possible to carry to the main functions of the developed control and management system:

- definition and release to the line of optimum number of the rolling stock per day;

- determination of optimum number of the rolling stock on the line in "rush hours";

- drawing up the optimum schedule for each bus every day;

- definition of a road situation in the current time point;

- expeditious updating of the schedule of the bus movement depending on a road situation;

- definition and adjustment of each bus movement speed depending on a road situation;

- definition of the schedule failure reason.

Estimating prospect of these or those directions of further city passenger transport development, it is necessary to remember that, first of all, it is necessary to find balance between the interests of consumers of transport services and transport enterprises that can be provided with application for these purposes of the transport systems modeling modern methods.

\section{References}

[1] Napkhonenko N.V. (1984) Investigation of the efficiency issues and quality of vegetables transportation by road: abstract of dissertation, Candidate of Economic Sciences. M.: Moscow Institute of Managemen, p. 19

[2] Napkhonenko N.V. (2003) Optimization of logistical flows in "consignor-consignee" system for agricultural enterprises. Universities Messenger. North-Caucasus Region. Technical Sciences. Special Issue, pp. 141-146.

[3] Napkhonenko N.V. "Logistic approach to the organization of agricultural products transportation", SRSTU (NPI) Messenger. Social-Economic Sciences Series, No. 6,(2015), pp. 119-127.

[4] Lukinsky V.S., Logistics of Motor Transport, Moscow: Finance and Statistics, (2000).

[5] Savin V.I. Cargo transportation by road: reference book, Moscow: "Business and Service", (2002).
[6] Savin V.I. Cargo transportation by road: reference book. - 2nd edition, updated and revised, Moscow: Publishing house "Business and Service", (2004), p. 544.

[7] Transportation-production processes in mechanized agricultural production // Classification, estimation and calculation methods. GOST 174600-72, Moscow: Federal Standardization Committee of the Cabinet of Ministers of the USSR, (1982), p. 27.

[8] Velmozhin A.V., Gudkov V.A., Mirotin L.B. The theory of organization and management of road transport: a logistical aspect of transportation processes formation, Volgograd: RPK "Polytechnic", (2001), p. 179

[8] Terterov M.N., Leontiev A.P. Preparation and transportation of perishable goods, Moscow: Transport, (1983).

[10] Tatuev A.A., Rokotyanskaya V.V., Kiseleva N.N., Zhankaziev A.H., Anvarovna A.S: Theoretical bases of socio-economic modernization management of the region, Social Sciences (Pakistan), (2015).

[11] Yeldashov G.A. "Basics for contract agreement on gargo transportation by road transport” [Text], Transport law, № 4, (2006), p. 21

[12] Lukyanova O.V., Khusainov F.I. "Perspectives of competition between rail and road transport", Bulletin of transport information, No. 11, (2013), pp. 3-14.

[13] Goriainov O.M., Roslavtsev D.M. Motor transport in logistic systems and chains: monograph, Kharkiv: NTMT, (2009), p. 344.

[14] NerushYu.M. Supply and transport: effective interaction, Moscow: Economics, (1999).

[15] Zhankaziev S.V., Novikov A.N., Vorobyev A.I., Kulev A.V., Morozov D.Y. "Efficiency of operation and functioning of the system of an indirect transport flow regulation and control", International Journal of Applied Engineering Research, 2017.

[16] Albekov A.U., Parkhomenko T.V., Polubotko A.A. "Green logistics in Russia: The phenomenon of progress, economic and environmental security", European Research Studies Journal, (2017). 